\title{
Asset Prices, the Real Exchange Rate, and Unemployment in a Small Open Economy: A Medium-Run Structuralist Perspective
}

\author{
By Hian Teck Hoon and Edmund S. Phelps*
}

\section{Introduction}

The second half of the nineties saw a number of industrial economies experiencing a steady decline in the rate of unemployment and real exchange rate appreciation together with a stock market boom, brought about by anticipation of higher productivity fueling an increased future need for capital, unaccompanied by rising inflation (Phelps and Zoega, 2001). How well does the open-economy Keynesian model (Mundell, 1962, 1963) explain this phenomenon? In the small open economy version of this model with a given external real rate of interest under freely fluctuating exchange rates and perfect international capital mobility, the stock market boom increases both investment and consumer spending, thus aggregate demand. The expanded demand, however, puts an upward pressure on the domestic interest rate, which leads to a massive inflow of capital and consequently a real exchange rate appreciation. The result is that export demand is fully crowded out so as to leave output and employment unchanged. In a large open economy, the increased aggregate demand pushes up the world interest rate so that the higher velocity of money pulls up domestic output and employment (above the natural level), creating inflationary pressures.

\footnotetext{
* Singapore Management University and Columbia University, respectively.
} 
In this paper (as well as in Hoon and Phelps, 2001), we explore non-monetary channels through which the rise in asset prices and the accompanying real exchange rate appreciation produce shifts in the natural rate path, even in a small open economy where the external real rate of interest is unaffected by the shock under study. In our earlier paper, we studied a customer market model where the underlying domestic asset is the firm's stock of customers, and the Law of One Price fails because of imperfect information regarding prices of similar or identical goods overseas. With the valuation of an additional customer increased due to an anticipated future step-increase in the level of productivity, firms are willing to reduce their current mark-ups. With the price reduced as a ratio to unit cost, each firm's real demand wage is increased accordingly, so employment is expanded. Moreover, with domestic firms facing an internationally more competitive environment, they are induced to reduce their markups even further so as to prevent the erosion of their customer base to foreign suppliers. Overall, employment expands without producing inflationary pressures.

Here, we shall explore a different, yet complementary, channel through which a rise in asset prices and real exchange rate appreciation lead to an expansion of employment without raising inflation. The failure of the Law of One Price is due to the BalassaHarrod-Samuleson assumption of a non-tradable sector, which we treat as the capitalgoods producing sector, lying alongside the tradable sector. Following the empirical literature (see Obstfeld and Rogoff, 1996), we suppose that the non-traded good sector is relatively labor intensive. When the stock market boom occurs, there is an increased 
demand for investment goods. However, the presence of external costs of adjustment, which we model by introducing the classic two-sector structure, means that there is an upward-sloping supply curve of capital good. (Goolsbee, 1997, presents empirical evidence in support of the existence of a positively-sloped supply curve of capital goods. He finds that a 10 percent investment tax credit increases equipment prices 3.5 to 7.0 percent. This lasts several years and is largest for assets with large order backlogs or low import competition. Capital goods workers' wages rise, too.) The increased demand for the investment good is, therefore, not fully met by increased supply, prompting a rise in the relative price of the non-traded capital good, and hence a real exchange rate appreciation. As the investment good sector is also the relatively labor-intensive one, there is an implied rise in the real demand wage, and a decline in equilibrium unemployment.

Our model can also be applied to study other shocks. A particularly striking example of the distinctive mechanism that we emphasize comes from contrasting our model's prediction about the effects of a rise in the external rate of interest to the prediction of the Mundell-Fleming model. Blanchard, in commenting on Fitoussi, Jestaz, Phelps and Zoega (2000), stresses that there has been a convergence in the views of a large number of economists regarding the common set of economic shocks that produced the great slump of Europe. In particular, it is now widely accepted that a rise in the world real interest rate in the eighties has contributed to a rise in European unemployment. Yet, according to the Mundell-Fleming model, an increase in the external real interest rate leads to a real exchange rate depreciation for the small open economy, thus stimulating 
export demand and hence expanding output and employment. (As a matter of fact, the neoclassical theory of business cycle fluctuations that relies on the intertemporal substitution of leisure mechanism to explain employment fluctuations would also predict that a rise in the external real rate of interest is expansionary. See Faria and LeónLedesma, 2000.) In our present model, the rise in the external real interest rate causes a fall in asset prices as managers apply a higher discount rate to evaluate the stream of prospective profits. The implied decline in investment spending leads to a movement down the capital-goods supply curve, with a consequent fall in the relative price of capital, a real exchange rate depreciation, and a decrease in the real demand wage. Given the wage curve, equilibrium employment declines.

Another shock we study in this paper is the adoption of investment tax credits, such as under Ronald Reagan in the first half of the eighties. We show that in our model economy, investment subsidies act to raise the relative price of capital, produce a real exchange rate appreciation, and both increase wages as well as expand equilibrium employment. In the rest of the paper, we first develop the basic model, and then apply it to study the anticipation of a future step-level increase in productivity, an increase in the external real rate of interest, and an introduction of investment tax credits.

\section{The Basic Model}

There are two goods in the economy, one a tradable consumption good and another a non-tradable capital good. For simplicity, the production of the capital good requires only labor, so capital is demanded as an input solely by the consumption good sector. There is 
perfect labor mobility across the two sectors. The production function of the capital good is given by $z_{N}=\varepsilon L_{N}$, where $z_{N}$ is the output supplied of the capital good, $L_{N}$ is the number of workers employed in the capital goods producing sector, and $\varepsilon$ is an effort function whose arguments we specify later. Profit maximization by capital goods producing firms leads to

$$
\text { (1) } v^{\mathrm{d}}=\varepsilon p_{N} \text {, }
$$

where $v$ is the real wage measured in terms of the consumption good, our numeraire, and $p_{N}$ is the relative price of the capital good. (The superscript " $\mathrm{d}$ " denotes the real demand wage.) Note that $p_{N}$ is also the real exchange rate.

The production function of the tradable good, a pure consumption good, exhibits constant returns to scale and is given by $z_{T}=A_{T} F\left(K, \varepsilon L_{T}\right)$, where $z_{T}$ is the domestic output of the consumption good, $K$ is the stock of capital, $L_{T}$ is the number of workers employed in the consumption goods producing sector, and $A_{T}$ is a measure of Hicks-neutral technical progress. Competitive hiring of workers leads to

(2) $v^{\mathrm{d}}=\varepsilon A_{T}\left[f\left(K / \varepsilon L_{T}\right)-\left(K / \varepsilon L_{T}\right) f^{\prime}\left(K / \varepsilon L_{T}\right)\right]$, where $f^{\prime}\left(K / \varepsilon L_{T}\right)>0$ and $f^{\prime \prime}\left(K / \varepsilon L_{T}\right)<0$. We suppose that there is an installation cost incurred in making capital operational in the consumption goods sector, given by $C(I)$, with $C^{\prime}(I)>0$ and $C^{\prime}{ }^{\prime}(I)>0$. For simplicity, we assume a quadratic cost function so $C(I)=h I^{2} / 2$, $h>0$. Taking the external real rate of interest as given, perfect international capital mobility leads to $r=r^{*}$, a parameter. Solving the firm's optimization problem leads to the following pair of equations:

(3) $I^{\mathrm{d}}=\left(q-p_{N}\right) / h$, 


$$
\left(r^{*}+\delta\right) q=A_{T} f^{\prime}\left(K / \varepsilon L_{T}\right)+(d q / d t)
$$

where $q$ is the shadow price of capital, and $I^{\mathrm{d}}$ is investment demand. We note from (3) that, given $q$, investment demand is decreasing in $p_{N}$. An increase in $q$ shifts out the investment demand schedule. Equating (1) and (2), we note that $K / \varepsilon L_{T}$ is a positive function of $p_{N} / A_{T}$, that is, $K / \varepsilon L_{T}=\phi\left(p_{N} / A_{T}\right), \phi^{\prime}\left(p_{N} / A_{T}\right)>0$. Substituting this result in (4), we get

$$
\left(r^{*}+\delta\right) q=A_{T} f^{\prime}\left(\phi\left(p_{N} / A_{T}\right)\right)+(d q / d t)
$$

Let the fixed size of the labor force be given by $L$. Then the size of the employed workforce is given by $(1-u) L$, where $u$ is the rate of unemployment. We can express the output supply of the capital good as:

(6) $\quad z_{N}=\varepsilon(1-u) L-\left[K / \phi\left(p_{N} / A_{T}\right)\right]$.

To determine the equilibrium rate of unemployment, we draw upon a shirking formulation of the labor market (Phelps, 1994). Each firm in the economy is assumed to choose a wage policy so as to minimize the effective $\operatorname{cost}, v / \varepsilon$, where the effort function depends negatively on its two arguments: $z / v$ and $y^{\mathrm{w}} / v$. Here, $z$ is the wage expected elsewhere, which we take to be equal to $(1-u) v^{\mathrm{e}}$, and $y^{\mathrm{w}}$ is the nonwage income, which we take as fixed for a medium-run analysis. Cost minimization by choice of an optimal supply wage yields the generalized Solow elasticity condition:

$$
\text { (7) } 1=-\left[\left(\varepsilon_{1} / \varepsilon\right)(z / v)+\left(\varepsilon_{2} / \varepsilon\right)\left(y^{\mathrm{w}} / v\right)\right] \text {. }
$$

Noting that under a consistent expectations equilibrium, $v=v^{\mathrm{e}}$, using the identity $\mathrm{z} \equiv(1-$ $u) v^{\mathrm{e}}$, and treating $y^{\mathrm{w}}$ as fixed, we make the supply wage an increasing function of $1-u$, 
that is, $v^{\mathrm{s}}=\mathrm{V}^{\mathrm{s}}\left(1-u ; y^{\mathrm{w}}\right), \mathrm{V}_{1-u}^{\mathrm{s}}>0$. An increase in nonwage income raises the supply wage at any given employment rate. Note from (7) that, in equilibrium, we have the following restrictions on the partial elasticities: $0<-\left(\varepsilon_{1} / \varepsilon\right)(1-u)<1$ and $0<-\left(\varepsilon_{2} / \varepsilon\right)\left(y^{\mathrm{w}} / v\right)<1$. In the Marshallian employment—real wage plane, the wage curve is upward sloping. To depict the demand wage curve, we note from (1) that given $p_{N}$, the demand wage declines as 1-u increases:

$$
d v^{\mathrm{d}} / d(1-u)=p_{N} \varepsilon_{1} /\left[1+\left(\varepsilon_{2} / \varepsilon\right)\left(y^{\mathrm{w}} / v\right)\right]<0
$$

since around the equilibrium, $0<-\left(\varepsilon_{2} / \varepsilon\right)\left(y^{\mathrm{w}} / v\right)<1$, and $\varepsilon_{1}<0$. The intuition is that as the labor market tightens, workers' work effort declines since they can more readily find alternative employment elsewhere in the event that they are caught shirking and are fired. So the demand wage curve is downward sloping in the Marshallian employment-real wage plane. Juxtaposed against the equilibrium wage curve, the intersection gives the pair of equilibrium wage and employment rate. An increase in the relative price of the capital good, equivalently a real exchange rate appreciation, shifts up the demand wage curve along the given wage curve, and so raises both the real wage as well as the equilibrium employment. (It would seem from (2) that at given 1-u, the real demand wage depends on both $p_{N}$ and $A_{T}$. However, since workers are freely mobile across the two sectors, an increase in $A_{T}$ would prompt an influx of workers into the tradable sector at given $p_{N}$, thus lowering $K / \varepsilon L_{T}$ sufficiently to make the labor value marginal product unchanged at given $p_{N}$.) We can write the demand wage as a decreasing function of $1-u$, given $p_{N}$, that is, $v^{\mathrm{d}}=\mathrm{V}^{\mathrm{d}}\left(1-u ; p_{N}\right), \mathrm{V}^{\mathrm{d}} 1-u<0$. Equating $\mathrm{V}^{\mathrm{s}}\left(1-u ; y^{\mathrm{w}}\right)$ to $\mathrm{V}^{\mathrm{d}}\left(1-u ; p_{N}\right)$, we can simply write 1-u $=\mu\left(p_{N} ; y^{\mathrm{w}}\right)$, with 1-u increasing in $p_{N}$, given $y^{\mathrm{w}}$. 
We see that when a real exchange rate appreciation occurs, equilibrium employment is increased and the real wage rises. In our shirking model, the tighter labor market condition can lead to less work effort being exerted as workers reckon that they can more readily find alternative employment elsewhere should they be caught shirking and be fired. If, however, we suppose that the reduced work effort on account of better employment opportunities does not paradoxically cause the total effective workforce to decline, then $\varepsilon(1-u) L$ will be an increasing function of $p_{N}$. Using this result in (6), we obtain a reduced form expression for the output supply of the capital good:

(9) $\quad Z_{N}=Z_{\mathrm{N}}\left(p_{N}, K ; A_{T}\right)$,

where the output supply of the capital good increases in $p_{N}$, and decreases in $K$ and $A_{T}$.

Equating investment demand given by (3) to the output supply of the capital good given by $(9), I^{\mathrm{d}}=\mathrm{z}_{\mathrm{N}}$ :

$$
\left(q-p_{N}\right) / h=\mathrm{Z}_{\mathrm{N}}\left(p_{N}, K ; A_{T}\right),
$$

so $q$ is an increasing function of $p_{N}$, and a decreasing function of $K$ and $A_{T}, q=\varphi\left(p_{N}, K\right.$; $\left.A_{T}\right)$. Alternatively, $p_{N}$ is an increasing function of $q, K$ and $A_{T}, p_{N}=\omega\left(q, K ; A_{T}\right)$.

The key dynamics of our model can now be represented by the following pair of equations:

$$
\begin{aligned}
& d K / d t=Z_{\mathrm{N}}\left(p_{N}, K ; A_{T}\right)-\delta K, \\
& \varphi_{1}\left(d p_{N} / d t\right)=\left(r^{*}+\delta\right) \varphi\left(p_{N}, K ; A_{T}\right)-A_{T} f^{\prime}\left(\phi\left(p_{N} / A_{T}\right)\right)-\varphi_{2}\left[Z_{N}\left(p_{N}, K ; A_{T}\right)-\delta K\right],
\end{aligned}
$$


where $\varphi_{1}>0$, and $\varphi_{2}<0$. We can check readily that the stationary locus for $d K / d t=0$ is positively sloped, with a gradient given by

$$
d p_{N} /\left.d K\right|_{\mathrm{KK}}=\left[\delta-\partial \mathrm{Z}_{\mathrm{N}} / \partial K\right] /\left(\partial \mathrm{Z}_{\mathrm{N}} / \partial p_{N}\right)>0 .
$$

The stationary locus for $d p_{N} / d t=0$ is also positively sloped, with a gradient given by

$$
d p_{N} /\left.d K\right|_{\mathrm{PP}}=\left\{\left[\delta-\partial \mathrm{Z}_{\mathrm{N}} / \partial K\right]+\left(r^{*}+\delta\right)\right\} /\left\{\partial \mathrm{Z}_{\mathrm{N}} / \partial p_{N}+\left(f^{\prime} \phi^{\prime} / \varphi_{2}\right)-\right.
$$

$$
\left.\left(\left(r^{*}+\delta\right) \varphi_{1} / \varphi_{2}\right)\right\}>0
$$

noting that $f^{\prime}<0, \phi^{\prime}>0, \varphi_{1}>0$, and $\varphi_{2}<0$. For a sufficiently low $r^{*}, d p_{N} /\left.d K\right|_{\mathrm{PP}}<d p_{N} /\left.d K\right|_{\mathrm{KK}}$, and we obtain saddle-path stability, with the unique saddle path being positively sloped and having a smaller gradient than the two stationary loci. The phase diagram is shown in Figure 1.

We note that it is also possible to develop a phase diagram in the $(K, q)$ plane representing the following pair of equations:

$$
\begin{aligned}
& d K / d t=Z_{\mathrm{N}}\left(\omega\left(q, K ; A_{T}\right), K ; A_{T}\right)-\delta K \\
& d q / d t=\left(r^{*}+\delta\right) q-A_{T} f^{\prime}\left(\phi\left(\omega\left(q, K ; A_{T}\right) / A_{T}\right)\right) .
\end{aligned}
$$

The slope of the $K$-stationary locus is positive, while the $q$-stationary locus is negatively sloped:

$$
d q /\left.d K\right|_{\mathrm{KK}}=\left[\delta-\left(1+\mathrm{h} \partial \mathrm{Z}_{\mathrm{N}} / \partial p_{N}\right)^{-1} \partial \mathrm{Z}_{\mathrm{N}} / \partial K\right] /\left(\omega_{1} \partial \mathrm{Z}_{\mathrm{N}} / \partial p_{N}\right)>0
$$


$d q / d K \mid \mathrm{qq}=\omega_{2} f^{\prime} \phi^{\prime} /\left[\left(r^{*}+\delta\right)-\omega_{1} f^{\prime} \phi^{\prime}\right]<0$,

where $\omega_{1}>0$ and $\omega_{2}>0$. We obtain a negatively-sloped unique saddle path (see Figure 2 ).

\section{Analysis of Shocks}

An anticipation of a future step-increase in $A_{T}$

Suppose that at the current moment, $t_{0}$, economic agents form an expectation that at some point in the future, $t_{1}$, there will be a step increase in $A_{T}$. In the phase diagram in the $(K$, $\left.p_{N}\right)$ plane, the stationary locus for $d K / d t=0$ shifts to the left as the output supply of the capital good is reduced by the increase in $A_{T}$, as labor is drawn into the tradable sector, necessitating an increase in $p_{N}$ to replace depreciation at any $K$. We can also check that the stationary locus for $d p_{N} / d t=0$ is shifted leftwards, hence upwards. Hence on impact, there is an upward jump of $p_{N}$, which can be explained as follows: With prospects of a higher stream of profits in the future brought about by better technology raising the productivity of capital, there is an upward jump of current $q$, which stimulates investment demand. As the supply of capital is not perfectly elastic, there is an upward pressure on the relative price of the capital good, which being relatively labor intensive, pulls up the demand wage along the given wage curve, and being nontradable, leads to a real exchange rate appreciation. The temporarily depressed rental requires an expectation of capital gains so $q$ and $p_{N}$ continue to rise between $t_{0}$ and $t_{1}$. It is clear that when the technology improvement occurs at $t_{1}, q$ cannot jump at that point. So it is $p_{N}$ that must rise at that point to reconcile the investment demand to the reduced supply of the capital good as workers are released from the capital goods producing sector to the consumer good sector. Although the relative price of the capital good is unambiguously increased in the 
new steady state, there are two possible paths $p_{N}$ could take to reach that steady state: a monotonic increase in the one case, incorporating the jump at $t_{1}$, and an overshooting above the steady-state $p_{N}$ in the other case.

A rise in the external real rate of interest

An increase in $r^{*}$ leads to a downward shift of the $d p_{N} / d t=0$ stationary locus along the unshifted $d K / d t=0$ locus in Figure 1 . There is an immediate drop of $p_{N}$ followed by a steady decline to reach a permanently lower level. The intuition is that the higher discount rate applied by managers to evaluate prospective profits causes a fall in $q$, which contracts investment demand. Given an upward-sloping supply curve for capital, there is a fall in the relative price of capital, which reduces the demand wage and consequently equilibrium employment contracts.

\section{An introduction of an investment tax credit}

The introduction of an investment tax credit, say at the rate of $s$, and financed by a lumpsum tax, makes the relative price of capital faced by the consumer good firm equal to (1s) $p_{N}$. Equation (3) is now amended to

$$
\text { (3') } \quad I^{\mathrm{d}}=\left[q-(1-s) p_{N}\right] / h \text {, }
$$

while (10) is amended to

$$
\left(10^{\prime}\right) \quad\left[q-(1-s) p_{N}\right] / h=Z_{\mathrm{N}}\left(p_{N}, K ; A_{T}\right)
$$

so $q$ is an increasing function of $p_{N}$, and a decreasing function of $K, s$, and $A_{T}, q=\varphi\left(p_{N}\right.$, $\left.K ; A_{T}, s\right)$. The introduction of an investment tax credit, therefore, leads to an upward shift 
of the $d p_{N} / d t=0$ stationary locus along the unshifted $d K / d t=0$ locus in Figure 1 . The stimulus to investment demand leads to a rise in the relative price of capital, a real appreciation, and an expansion of equilibrium employment.

\section{Concluding Remarks}

In this paper, we have drawn together elements of an incentive-wage labor market and an assets view of labor demand to show how various shocks in the international economy can explain some historical episodes that we argue the Keynesian paradigm cannot adequately explain. In our theory, perceptions of a bright future lead to a rise in share prices, which in turn stimulate employment without causing inflationary pressures. There are various assets that firms are then induced to invest in: the stock of customers both at home and overseas, trained employees who need firm-specific training to be fully functional, and fixed capital. In this paper, our emphasis has been on the third kind of capital---equipment and structures. We combine internal and external adjustment costs to generate an explicit firm investment demand function as well as an upward-sloping supply curve of capital. The result is a tractable model that can be used to generate useful insights into the general-equilibrium workings of an economy in response various economic shocks, highlighting the role of asset prices and the real exchange rate in determining labor market outcomes. 


\section{References}

Faria, João Ricardo and León-Ledesma, Miguel, 2000, “The Intertemporal Substitution Model of Labor Supply in an Open Economy," manuscript.

Jean-Paul Fitoussi, David Jestaz, Edmund S. Phelps and Gylfi Zoega, 2000, "Roots of the

Recent Recoveries: Labor Reforms or Private Sector Forces?” including Comments and Discussion, Brookings Papers on Economic Activity, 1, pp. 237-311.

Goolsbee, Austan, 1997, “Investment Tax Incentives, Prices, and the Supply of Capital Goods,” Quarterly Journal of Economics, August, pp. 121-148.

Hoon, Hian Teck and Edmund S. Phelps, 2001, “A Structuralist Model of the Small Open Economy in the Short, Medium and Long Run," manuscript, Singapore Management University and Columbia University.

Mundell, Robert A., 1962, “The Appropriate Use of Monetary and Fiscal Policy under Fixed Exchange Rates," IMF Staff Papers, March, 9, pp. 70-79.

Mundell, Robert A., 1963, “Capital Mobility and Stabilization Policy under Fixed and Flexible Exchange Rates," Canadian Journal of Economics and Political Science, November, 29, pp. 475-485. 
Obstfeld, Maurice and Kenneth S. Rogoff, 1996, Foundations of International Macroeconomics, Cambridge, Mass.: MIT Press.

Phelps, Edmund S., 1994, Structural Slumps: The Modern-Equilibrium Theory of Unemployment, Interest, and Assets, Cambridge, Mass.: Harvard University Press.

Phelps, Edmund S. and Gylfi Zoega, 2001, "Structural Booms," Economic Policy, April, pp. 85-126. 


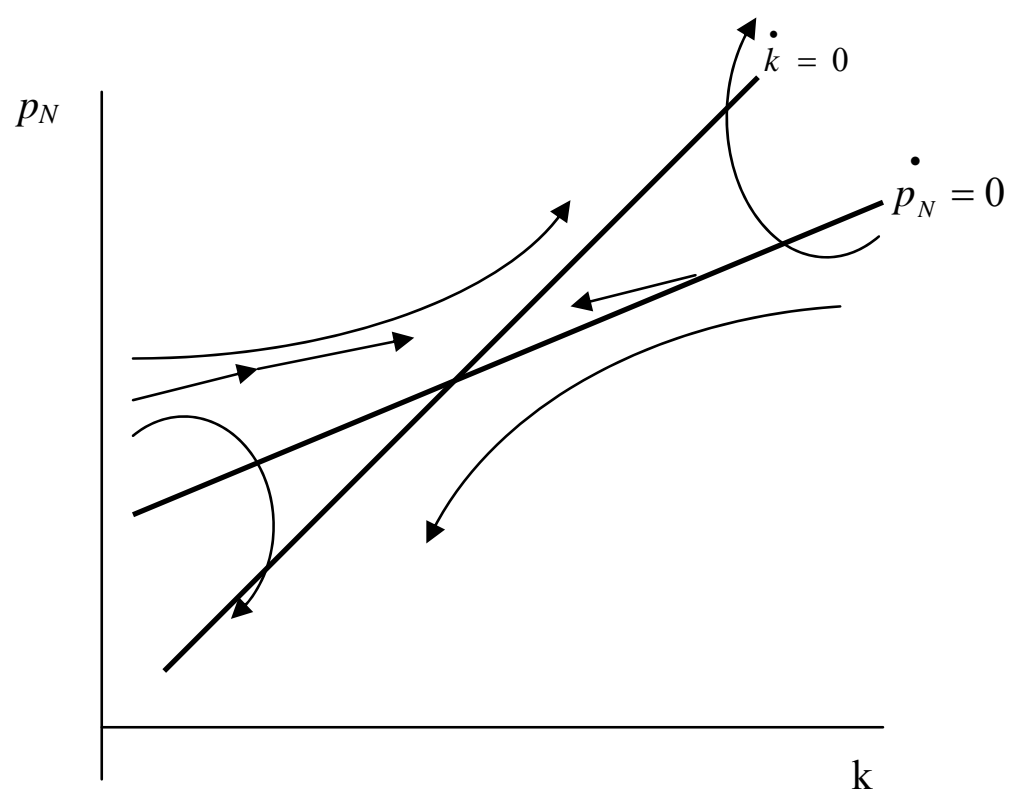

Figure 1. Phase Diagram in $\left(k, p_{N}\right)$ plane

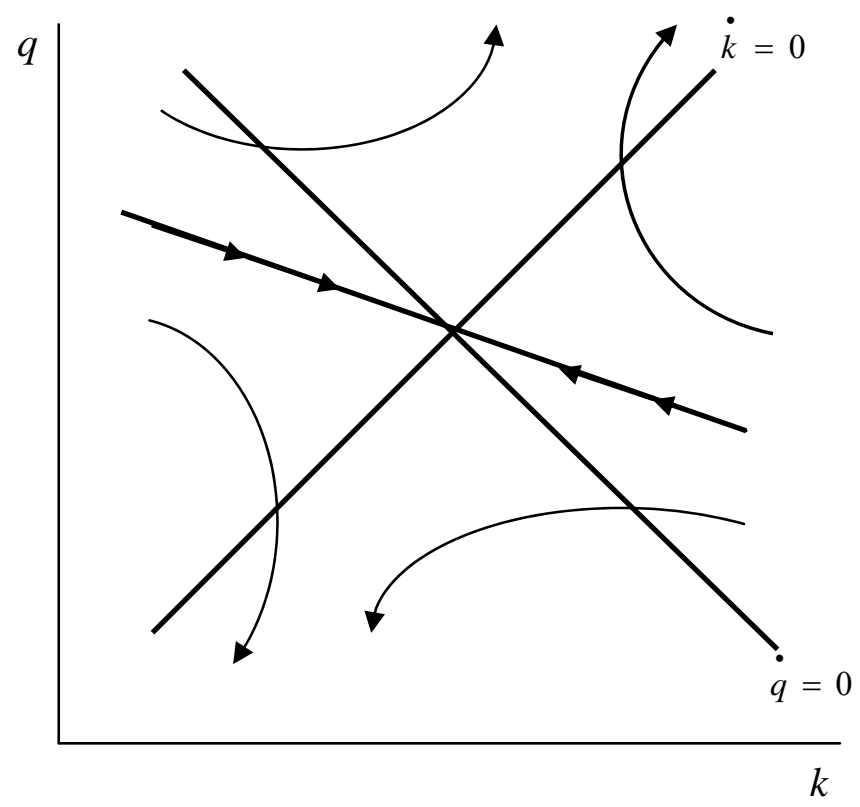

Figure 2. Phase Diagram in $(k, q)$ plane 